\title{
O INDÍGENA ORIGINARIO CAMPESINO E O ESTADO PLURINACIONAL DA BOLÍVIA
}

THE INDIGENOUS ORIGINARY CAMPESINO AND THE

PLURINATIONAL STATE OF BOLIVIA

RESUMO: A partir da contextualização do processo constituinte boliviano, que se transformou no marco de "criação" de um novo sujeito - o indígena originário campesino - e da reconceituação de povo, nação, etc., o presente trabalho apresenta uma reflexão sobre as tensões geradas por essas novidades do Estado Plurinacional em uma realidade ainda marcada pelo colonialismo. O problema proposto será analisado a partir de uma revisão da literatura para desvendar os desafios da mudança paradigmática que o constitucionalismo indígena representa, em especial sobre o sujeito dos direitos indígenas ora previstos e sobre a relação entre as distintas ordens jurídicas.

\section{Palavras-chave: Constitucionalismo.} Plurinacionalidade. Identidade.
ABSTRACT: From bolivian constitutional process context, which has become the outset to the "creation" of a new subject - "indígena originario campesino" - and the reconceptualization of people, nation, etc., this paper presents a reflection on tensions generated by this news brought by the Plurinational State into a reality still marked by colonialism. The proposed issue shall be analyzed from a literature review to uncover challenges from the paradigm shift that this indigenous constitutionalism represents, especially on the subject of indigenous rights and the relationship between many legal orders.
Indígenas. Keywords: Constitutionalism. Indigenous. Plurinationality. Identity.

\footnotetext{
${ }^{1}$ Doutorando em Teoria e Filosofia do Direito na Universidade Estadual do Rio de Janeiro.
} 


\section{INTRODUÇÃO}

As nações e povos indígenas bolivianos, oprimidos desde o primeiro contato com o mundo europeu, conseguiram pela primeira vez inscrever suas demandas dentro de um modelo de estado e do constitucionalismo trazidos da Europa. A Constituição Política do Estado de 2009 é um dos maiores exemplos de interculturalidade já vivenciados na América Latina: desde uma tradição europeia se busca afirmar o originário andino.

Passada uma década do início da assembleia constituinte, com toda a recepção calorosa que essa contribuição trouxe a Teoria do Estado, ao Direito Constitucional e ao constitucionalismo, já é possível perceber algumas das contradições que essa estratégia aventa. De todo modo, o processo de levante indígena já implicou em transformações reais e na articulação de novas estratégias. Entre elas, a (auto) afirmação de um novo sujeito, protagonista desse processo, que é o Indígena Originário Campesino; e, conjuntamente, a transformação dos conceitos de nação e povo boliviano.

Em um primeiro momento, parecia coerente afirmar que se tratava de uma consequência da evolução do Direito Internacional, fruto da Convenção 169 da Organização Internacional do Trabalho, que previa princípios que se mostraram importantes, como a autodeterminação. Sem desconsiderar o suporte que essa convenção e as previsões multiculturais trouxeram para nossa compreensão do processo de ascensão da reivindicação étnica ou cultural por autonomia, na Bolívia foram movimentos sociais, de distintas origens e tradições de organização (sindicais ou originarias), que cunharam a ideia de um Estado plurinacional a ser ratificado por uma assembleia constituinte.

Ou seja, este é um projeto que nasce da articulação direta dos interessados - desde baixo - com a intenção expressa de descolonizar e refundar o Estado do qual nunca se sentiram parte. Trata-se, antes de tudo, de uma tomada consciente do Estado; muito maior que o desenvolvimento das leis internacionais ou da consciência multicultural de indigenistas

O presente trabalho apresenta uma reflexão sobre o constitucionalismo indígena na América Latina, tendo como objeto o caso da Bolívia, que teve seu Estado refundado pela 
nova constituição de 2009, com um texto que se dedica à superação da herança colonialista, valorizando a cultura milenar dos povos e nações que habitam o país. A justificativa que motivou a elaboração deste artigo foi a escassez de trabalhos acadêmicos que pretendam compreender a dinâmica latino-americana e seu papel na elaboração de soluções para as necessidades do próprio continente.

O problema proposto trata da necessidade de refletir sobre os desafios apontados a partir da mudança paradigmática que o constitucionalismo indígena representa, em especial sobre o sujeito dos direitos indígenas ora previstos (em uma sociedade composta por pessoas que possuem uma identidade e uma forma de vida intermediária entre o indígena e o não indígena ou "ocidental") e sobre a relação entre as distintas ordens jurídicas (limite do direito indígena quando alcança direitos fundamentais, inserido em todos os textos constitucionais da América Latina).

A partir de uma revisão da literatura latino-americana sobre o tema, é demonstrada a seguinte hipótese: não basta o texto constitucional constatar a plurinacionalidade boliviana ou, ainda, reconhecer direitos indígenas, para que as pessoas vivam em pé de igualdade material. O constitucionalismo indígena representa um passo na busca pela superação por motivos culturais, mas ainda persistem diferenças de ordem econômica, que determinam a titularidade prática dos direitos fundamentais.

\section{UMA REFUNDAÇÃO DESDE ABAIXO}

A relevância do proceso de cambio boliviana para o os outros povos indígenas latino-americanos se explica pela composição de sua população com $2 / 3$ se identificando como indígena e mestiça (CENSO, 2001), com dois terços se auto identificando com a herança dos povos originários. Trata-se de um país composto por, pelo menos entre as reconhecidas oficialmente, trinta e seis nações diversas com idiomas próprios, sistemas econômicos, território, etc. Todas se articulam ao longo do processo para recusar o tratamento de meras etnias ou culturas diferenciadas (HARNECKER; FUENTES, 2008, p. 140), e se afirmar como nações. Ou seja, trata-se de uma maioria demográfica que almeja cumprir o papel de maioria política, assumindo o poder depois de séculos de exclusão colonial. 
Não que tenha sido necessário esperar o reconhecimento por parte do Estado boliviano: são nações e povos que sempre exercitaram uma "autonomia de fato" dentro de uma Bolívia que sempre comportou duas realidades nunca conciliadas: uma do Estado boliviano, outra das nações organizadas. Entre as formas de organizações originarias, estão o ayllu e a marka: formas comunitárias familiares, que partem de um parentesco presumido ou não, de membros que trabalham na mesma terra. Isso possibilitou que mantivessem a importância de sua organização social e o aprofundamento teórico/filosófico por trás das contribuições dos povos indígenas trouxeram ao constitucionalismo.

É nesse contexto - originário - que surge a assembleia constituinte, descrita na etnografia realizada por Salvador Schavelzon (2010) como a chegada de novos atores, indígenas e camponeses, ao Estado. Como observa Schavelzon (2009, p. 35): “' $O$ ' indígena - talvez mais do que 'os' indígenas - está no centro da fase política iniciada com a chegada do MAS-IPSP ao poder, com Evo Morales".

A estratégia que adotaram foi se apropriar do instrumento "constituição", forçando o Estado a reconhecer que não se tratam de culturas diferenciadas, mas de verdadeiras nações. Deste modo, refundando o Estado para a nova ideia de povo boliviano, que precisa ser plurinacional de modo a incorporá-los de forma não-subordinada.

Esse proceso de cambio parte da auto identificação como indígenas originários campesinos, um novo conceito indissociável, cumpre o papel de aglutinar povos e nações indígenas de terras altas e baixas da Bolívia, incluindo aqueles que por quaisquer motivos tenham adaptado as formas originarias de organização (como os ayllus e markas) sob novas consignais sindicais ou campesinas.

\section{A CONSTITUINTE (2006-2009) COMO MARCO DO PROCESSO}

A história recente da Bolívia, desde o início dos anos 2000, deve ser compreendida como um período de revoltas populares e acontecimentos históricos que confrontaram a política neoliberal (com um Estado, além de excludente, mínimo), e possibilitando florescer rapidamente a bandeira por uma Assembleia Constituinte. Mas desde a história mais remota de sua criação, é a desigualdade socioeconômica, sempre relacionada ao 
aspecto étnico, que apresenta a necessidade aos povos originários de um novo projeto de Estado não voltado exclusivamente para uma minoria branca criolla ou europeia.

Faz parte desse momento, demonstrando o caráter anti-neoliberal, as conhecidas "guerra da água" em Cochabamba, 2002 e a "guerra do gás" em Tarija, 2003; e a disputa pela nacionalização do petróleo em 2005, a partir de um referendo de 2004. Tudo culminando na consolidação do indianismo katarista com a candidatura e vitória, em 2005, do primeiro presidente de etnia aimará, Evo Morales, com inéditos $54 \%$ dos votos, pelo MAS-IPSP (Movimiento al Socialismo Instrumento Político por la Soberanía de los Pueblos).

A transformação da disputa nas ruas para a disputa eleitoral vai se dar a partir do "Pacto de Unidade" entre distintos movimento sociais, sindicais, indígenas, de bairros: um "pacto materializado em um documento que se constitui um verdadeiro mandato popular. Surge assim como um governo de novo tipo cuja legitimidade não vem exclusivamente do exercício eleitoral, mas também de uma escolha social" (MONCAYO, 2013, p. 155, tradução própria).

O Pacto da Unidade assinado em 2006 por organizações que tanto se declaravam camponesas - CSUTCB, colonizadores, e a Central de Mulheres Camponesas Bartolina Sisa - quanto originárias - o Conamaq das terras altas, e Cidob das terras baixas participarão ativamente do assessoramento da Constituinte (SCHAVELZON, 2010, p. 73-107). É resultado disso o fato do programa de governo masista ser marcado pela Agenda de Outubro (uma agenda criada em meio aos protestos populares), que se dedica -primeiro à nacionalização dos campos de gás e, posteriormente, a convocatória de uma Assembleia Constituinte.

Como foi citado inicialmente, esse projeto político influenciado pelo indianismo katarista e por movimentos de esquerda e sindical, ocorre em meio ao desenvolvimento do direito internacional sobre os povos indígenas, como a Convenção 169 da OIT e a Declaração dos Direitos dos povos indígenas da ONU de 2007, mas parte localmente das organizações indígenas e suas longas marchas (unitárias entre povos de terras altas e baixas) na década de 90 (OLIVEIRA FILHO, 2014a, p. 34). São povos de distintas tradições, os de terras altas (andinas) com grande expressão populacional; e os de terras baixas 
(como os amazônicos, guaranis, chiquitanos, ayoreos, guarayos, etc.) com parcelas menores e mais concentradas.

Um dos debates mais importantes travados na constituinte é o da definição do que constituía o povo boliviano. O projeto inicial do MAS foi transformado e ficou definido que nação boliviana é conformada pelos bolivianos e bolivianas, pelas nações e povos indígenas, e pelas comunidades interculturais e afro bolivianas (CPE, Art. $3^{\circ}$ ), sendo excluída do texto inicial a menção às comunidades urbanas de todas as classes sociais, demandada pelas correntes de esquerda. Consequentemente, a cidadania passa a assumir novas dimensões, assim como sua relação com a nacionalidade, identidade e cultura. Às nações e aos povos originários ou indígenas, protagonistas desse processo, são previstos direitos políticos específicos, rompendo lógica de igualdade formal do Estado liberal.

Entre as previsões inovadoras quanto à cidadania plurinacional está o direito ao voto e participação dos povos originários na Bolívia, inclusive o de realizar eleições de acordo com suas próprias regras. Os espaços políticos, como os parlamentos plurinacional e departamentais, ou os ministérios do Poder Executivo e a Corte Constitucional, deverão refletir proporcionalmente a composição da sociedade. Foram, ainda, previstos 36 idiomas oficiais além do castelhano, estando os governos obrigados a adotar ao menos dois idiomas - o castelhano e outra língua originária predominante naquele território. Pode parecer mais uma política multicultural, porém ultrapassa o mero reconhecimento e assume especial importância dada a proporção dos que falam línguas originárias (SCHAVELZON, 2010, p. 5).

Esse conjunto de transformações é apresentado pelos constituintes como uma Refundação do Estado, expressamente objetivando superar o colonialismo e o neoliberalismo. Fruto da conjuntura de afirmação das nações originárias e de uma proposta das organizações indígenas assumida pelo MAS, o caráter Plurinacional do Estado tornou-se o elemento mais importante do novo texto constitucional. Seu objetivo era superar dois modelos de Estado no que diz respeito à questão étnica: o monoculturalismo da assimilação e o multiculturalismo. Ao mesmo tempo simbolizava a construção coletiva de um pacto de Estado, que pela primeira vez conta com a participação ativa dos povos indígenas. 
Partindo das experiências vividas pelas comunidades interculturais, foram reconhecidas novas fontes de produção de Direito: jurisdição originária, indígena ou campesina, suas autoridades, instituições, práticas e costumes. Dessa forma, os povos e nações indígenas passam a ter garantidos sua cultura, mas também o direito ao autogoverno e à administração de conflitos. As jurisdições ordinárias e indígenas integram o Poder Judiciário em igual hierarquia com a justiça ordinária e suas decisões deverão se acatadas por todas as pessoas e autoridades públicas. Essas competências jurisdicionais são atribuídas e organizadas segundo uma lei de deslinde, estando limitadas ao direito à vida e aos outros direitos constitucionais.

O autogoverno e a livre determinação desses grupos estão previstos no capítulo que trata da "autonomia indígena originária campesina". As comunidades, nações ou povos que habitem territórios ancestrais podem elaborar um Estatuto próprio, organizando-se segundo seus próprios regulamentos, instituições, autoridades, procedimentos a fim de desenvolver e exercer as suas próprias instituições democráticas; de gerir e administrar seus recursos naturais; criar e administrar taxas, patentes e contribuições especiais em seu âmbito; administrar seus impostos; planificação e gestão de seu território, sistema elétrico, patrimônio cultural, natural, etc. (OLIVEIRA FILHO, 2014a, p. 37). A intenção não é só superar o passado do Estado moderno liberal, mas com ele paradigmas que não se adequaram à realidade andina, como a agenda do multiculturalismo e do neoliberalismo, ambos identificados com os governos da década de 90.

Direcionada à convivência plurinacional, a nova CPE possui como um dos fundamentos de seu projeto a criação de uma nova forma de gestão política de territórios: as Autonomias Indígenas Originárias Campesinas. Esse ente novo não só expressa a preocupação dos constituintes em se materializar os direitos previstos, mas carrega em sua definição um debate complexo entre os atores sociais que pensaram a nova CPE, de modo a incluir toda base da nova hegemonia (STEFANONI, 2006, p.37; VALENÇA, 2014, p.101) que surge durante as revoltas populares dos anos 2000.

Tudo isto conforma um processo de mudanças - ou proceso de cambio reconhecido pelas Nações e Povos Indígenas Originários Campesinos (NePIOCs) e que declara o objetivo de descolonização. A recepção das novas previsões, desde 
pesquisadores latino-americanos comprometidos com a questão indígena, é efusiva: parecia o primeiro passo de um processo de descolonização do poder e da justiça (WOLKMER; FAGUNDES, 2011, p. 378). Mas é a expectativa de um novo sujeito, criado no bojo deste processo, é que necessita ser correspondida.

\section{NOVOS CONCEITOS PARA EXPLICAR O NOVO SUJEITO}

Como se perceber, na Bolívia plurinacional, a nação moderna vai dar espaço ao povo: é na conceituação de povo boliviano que surge o novo sujeito indissociável chamado indígena originário campesino. 0 " $I O C$ ", esse novo sujeito sem separação por vírgulas, tal qual nossos nomes e sobrenomes, é fruto do acúmulo de

[...] setores dos sindicatos campesinos - que conduziram Evo Morales à política nacional - que viam na separação entre originários e campesinos a discriminação dos campesinos como não indígenas. A discussão conduzia ao tema de como nos últimos anos os sindicatos campesinos - e o próprio Evo Morales - assumiram uma identidade indígena, junto à de campesinos (SCHAVELZON, 2009, p. 41).

A intenção é encerrar o integracionismo (por exemplo, a transformação de indígenas em camponeses na Revolução de 52) ao mesmo tempo que se reconhece distintas formas de ser indígena, abrangendo "grupos étnicos nômades junto a comunidades camponesas com propriedade individual” (SCHAVELZON, 2010, p. 72-75). Esse entendimento é corroborado pela Ley $n^{\circ} 031$ Marco de Autonomías $y$ Descentralización "Andrés Ibáñez" de 2010 (LMAD):

Artículo 6, III, Naciones y Pueblos Indígena Originario Campesinos - Son pueblos y naciones que existen con anterioridad a la invasión o colonización, constituyen una unidad sociopolítica, históricamente desarrollada, con organización, cultura, instituciones, derecho, ritualidad, religión, idioma y otras características comunes e integradas. Se encuentran asentados en un territorio ancestral determinado y mediante sus instituciones propias, en tierras altas son los Suyus conformados por Markas, Ayllus y otras formas de organización, y en tierras bajas con las características propias de cada pueblo indígena, de acuerdo a lo establecido en el Artículo 2, el Parágrafo I del Artículo 30 y el Artículo 32 de la Constitución Política del Estado.

E, também:

Artículo 43 (CARÁCTER DE LO INDÍGENA ORIGINARIO CAMPESINO). Lo indígena originario campesino es un concepto indivisible que identifica a los pueblos y naciones de Bolívia cuya existencia es anterior a la colonia, cuya población comparte territorialidad, cultura, historia, lenguas y organización o instituciones 
jurídicas, políticas, sociales y económicas propias; y así se denominen solamente como indígenas o como originarios o como campesinos, pueden acceder en igualdad de condiciones al derecho a la autonomía establecido en la Constitución Política del Estado, en sus territorios ancestrales actualmente habitados por ellos mismos y en concordancia con el Artículo 1 del Convenio 169 sobre Pueblos Indígenas de la Organización Internacional del Trabajo. El pueblo afroboliviano está incluido en estos alcances, en concordancia con el Artículo 32 de la Constitución Política del Estado.

O texto da lei deve ser compreendido dentro da ressignificação dos conceitos de nação, identidade e etnia promovido pelo constitucionalismo indígena. Para os indígenas originários campesinos, a ideia de nação pode assumir dois significados e ser entendida como a nação liberal, enquanto cidadãos, ou etnocultural, enquanto povo (SANTOS, 2010, p. 122). A estratégia deles de adotar o formato de nação para si trata-se da luta pelo reconhecimento não só do caráter cultural de sua identidade, mas também de suas implicações jurídicas e políticas. Assim, acumulam na nacionalidade a identidade étnica e nacional, ressignificando-a e inserindo, daqui para a frente, essa transformação na Teoria do Estado e no Direito Constitucional.

Álvaro García Linera (2012, p. 39-41) explica que nações são artefatos políticos que criam um sentido de pertencimento a um tipo de entidade histórica, que congrega pessoas que não necessitam se conhecer, mas compartem laços básicos quanto a uma história compartilhada. São fronteiras sociais, territoriais e culturais que existem no imaginário dos nacionais, concretizando-se em estruturas materiais e institucionais. Portanto, nações prescindem a existência de comunidades étnicas para serem consolidadas; se constituem geralmente como uma junção política de muitas etnias, gerando uma nova. Fato que, todavia, não ocorreu na Bolívia, apesar de toda tentativa de integracionismo, resistindo com forças as identidades aimará e quíchua.

As etnias podem ser descritas como comunidades que compartilham atributos culturais e uma cosmologia baseada no compartilhamento de uma ancestralidade em comum: baseando-se em diferenças de natureza biológicas, linguísticas e religiosas, ou exclusivamente baseadas no idioma. A memória coletiva que forma permite o imaginário de "uma trajetória única" que diferencia o grupo dos demais; a linguagem como um "arquivo vivo" da visão de mundo em comum. Sustenta, ainda, a demanda por territórios 
considerados ancestrais, que servem referência para a base identitária e simbólica de uma etnia. O caminho das etnias pode perpassar a criação de um estado, ou tornar-se parte de um estado multinacional; podem existir como maiorias ou minorias. Além das ancestrais, há identidades produzidas pelo Estado, pela etnogênesis ou como produto de políticas coloniais (LINERA, 2012, p. 33-34).

Mas também é possível a convivência entre as duas identidades. $E$, dentro do "espectro do processo identitário", é possível que as identidades nacionais estejam mais diluídas quando comparadas às identidades étnicas; ou vice-versa (LINERA, 2012, p. 34). Esse é o caso da nacionalidade boliviana, que cumprirá o papel de uma segunda identidade, instrumentalizada conforme as situações concretas vivenciadas por seus membros. Por exemplo, o uso da nacionalidade boliviana quando da utilização de serviços públicos do Estado ou da identidade (agora nacionalidade também) aimará quando da solução de conflitos internos.

Para Linera (2012, p. 42), a identidade contemporânea aimará é, tal qual todas, uma construção com um objetivo de criar uma lealdade subjetiva entre os que se identificam, tornando visível e ressignificando elementos compartilhados como o idioma, a história, os ancestrais, a religião, entre outros. O diferencial da identidade aimará na Bolívia, além do tamanho populacional, foi sua capacidade de produzir "elites culturais" e "estruturas discursivas" fortes o suficiente para reinventar uma história autônoma visando um futuro autônomo, e uma liderança que dê visibilidade a estas demandas (LINERA, 2012, p. 44).

Não é incomum a existência de Estados com variados graus de multiculturalismo em seus territórios, desde a Índia à Bélgica. Desde o Canadá, autores como Charles Taylor e Will Kymlicka se dedicam a debater o multiculturalismo dentro do Estado-nação, observando que os cidadãos querem ter reconhecida sua autenticidade (TAYLOR, 1994, p. 28). E apresentando propostas como a constituição de cidadanias multiculturais (KYMLICKA, 1995), de modo a garantir a proteção externa de grupos culturais minoritários com relação às maiorias, a partir de garantias legais diferenciadas para a proteção de um estilo de vida autêntico.

Apesar das reformas multiculturais terem promovido o debate que levaria à proposta plurinacional, não foram adequadas para realidade boliviana. Na Bolívia, não há 
uma "maioria" determinante que sustente essa certeza de que um grupo nacional vai continuar sendo hegemônico em razão de seu tamanho populacional. A plurinacionalidade é um projeto local que parte da agenda do multiculturalismo para superá-lo: o "Estado Plurinacional se distinguia da experiência das reformas da década de 90, consideradas multiculturalistas e, portanto, um reconhecimento meramente teórico das diferenças, não realmente descolonizador e marcado ela sua cumplicidade com a república liberal" (SCHAVELZON, 2010, p. 71)

Portanto, uma das formas de compreender esta Constituição parte do entendimento do plurinacional como superação do multicultural, que pode ser deduzido tanto do texto da nova CPE quanto do processo constituinte boliviano. O multiculturalismo implicou transformações no tratamento dos povos indígenas das ex-colônias, embora não rompessem com o passado colonial persistindo sociedades hierárquicas e excludentes, que desconsideravam sua diversidade cultural e perpetuavam as relações de dominação colonial. Por outro lado, a plurinacionalidade consiste em reconhecer as identidades étnicas originárias como nacionalidades equiparando-as à nacionalidade boliviana.

Esse processo intercultural permeia todo o espírito da nova CPE, culminando em previsões constitucionais sobre as próprias nações e povos indígenas - e sua territorialidade, autogoverno, justiça originária - na direção ao almejado Estado Plurinacional. Uma das implicações é que esse Estado reconheça a existência de uma autonomia, baseada na resistência de formas de organizações comunitárias, como ayllu, sindicato, diretório e, mais recentemente, município. A intenção é incorporá-los ao novo Estado. No novo sistema constitucional, a Autonomia Indígena Originária Campesina (AIOC) é a alcunha que servirá como guarda-chuvas para organizar distintas nações e povos indígenas originários campesinos e todas essas formas de organização. É constitucionalmente positivado que a AIOC é o "âmbito de aplicação dos direitos indígenas no exercício de seus sistemas políticos, jurídicos e económicos conforme sua cosmovisão" (PLATA, 2009, p.247, tradução própria). 


\title{
5 AS AUTONOMIAS INDÍGENAS ORIGINÁRIAS CAMPESINAS E AS FRAGILIDADES DA ESTRATÉGIA CONSTITUINTE
}

A estratégia de encampar os espaços estatais vai se desenvolvendo desde a década de 90. A partir da Lei de Participação Política de 94, as NePIOCs vão se utilizar dos municípios como tática para ampliar sua de participação política, e com o tempo demandar a criação de municípios indígenas, com autoridades eleitas seguindo seus próprios costumes. Ainda que não atendidos, os "distritos indígenas" vão ser adotados para seguir essa direção, com subalcades eleitos segundo as tradições locais (ORTIZ e ZAMORANO, 2010, p.8).

Mas a autonomia das NePIOCs só ser plenamente projetada na Assembleia Constituinte de 2006-2009, embora tenha sido alterado a partir das reivindicações oposicionistas da Media Luna por autonomias departamentais. Tal acordo impediria que as autonomias servissem para ideais de "reconstituição do Qullasuyu" ${ }^{1}$ ou recuperação de terras perdidas na colonização. Graças à inclusão de uma frase, conforme aponta Salvador Schavelzon (2010, p. 457):

\begin{abstract}
O acordo congressual, também faria modificações que afetariam a autonomia indígena e, também, sua indefinição estratégica. No artigo 291 da Constituição aprovada em Oruro, estipulava-se que "A conformação de entidades territoriais indígenas originários camponesas baseia-se na consolidação de seus territórios ancestrais, e na vontade da sua população, expressada em consulta, conforme normas e procedimentos próprios [...]". Fazia-se lugar à reivindicação das organizações indígenas das terras altas (CONAMAQ) que impulsionavam há anos "a consolidação de territórios ancestrais". Na versão revisada pelo Congresso (artigo 290), estabelece-se que "A conformação da autonomia indígena originário camponês se baseia em territórios ancestrais, atualmente habitados por esses povos e nações, e na vontade de sua população, expressa em consulta, de acordo com a Constituição e a Lei [...]". É evidente como o adicionado "habitados por esses povos e nacionais" limita a quantidade de povo que poderão ascender à autonomia. (Grifo próprio)
\end{abstract}

No capítulo sétimo da Constituição boliviana, consta que a "autonomia indígena originária campesina" consiste na garantia autogoverno e livre determinação desses grupos. Ela é baseada nos territórios ancestrais, devendo passar por consulta e elaboração de um Estatuto próprio. Elas poderão ser unificadas à outras autonomias, e são exercidas segundo seus próprios regulamentos, instituições, autoridades, procedimentos, sempre em harmonia com a constituição (CPE, Art. 289, 290, I, II, Art. 292 e Art. 296). A lista de 
competência das autonomias é extensa, além das que podem ser transferidas ou delegadas. Há ainda competências compartilhadas e concorrentes com os outros entes do Estado Plurinacional (CPE, Art. 304, II).

Entre as competências exclusivas, pode desenvolver e exercer suas próprias instituições democráticas; gerir e administrar seus recursos naturais; criar e administrar taxas2, patentes e contribuições especiais em seu âmbito; administrar seus impostos; planificação e gestão de seu território, sistema elétrico, patrimônio cultural, natural, etc.

Um dos conflitos de competência que mais implicam na plurinacionalidade é a questão da justiça. Todas as autonomias são atreladas à existência da justiça originária indígena campesina (JIOC), na mesma hierarquia que a ordinária, segundo a CPE. Mas para realizar a JIOC é criada uma lei específica, a Ley de Deslinde Jurisdiccional, gerando controvérsias com as demandas das NePIOCs: não está claro se só as AIOCs poderão utilizar a justiça originária, ou também se poderiam usá-la todas as NePIOCs. Expressamente a Lei se aplica às AIOCs, o que não as exime de problemas: a lei limita demasiadamente e acaba colocando a JIOC abaixo da ordinária, uma vez que os casos mais importantes são mandados à ordinária.

Depois de 2010, elabora-se a Lei Marco de Autonomias, que estabelece certos requisitos e vias para aceder à condição de AIOC. Não há limite de quantas autonomias poderão ser criadas, o Ministério de Autonomias previa mais de 100 municípios poderiam transformar-se em AIOC, a partir de um diagnóstico de municípios com maioria da população indígena originária campesina que mantém a língua originária (ALBÓ; ROMERO, 2009). Nesse momento, havia um discurso muito forte de recuperar o indígena, mas em 2015 esse discurso foi perdendo forças, por questionamentos sobre o sistema de autonomias, interesses pessoais, a influência do municipalismo, etc.

Afinal, são povos indígenas, mas que foram por muito tempo colonizados, e que absorveram muito o tema do município. Por exemplo, para ser autonomia indígena é preciso prestação de contas para a população e há um maior controle das autoridades com a possibilidade de ser destituído. Então pode ser mais interessante para uma autoridade, pessoalmente, manter a forma de município. Neste, há maior estabilidade de governança, há leis que descrevem a duração do mandato e que impossibilitam a população destituir a 
autoridade quando quiser. Portanto, o número de AIOCs pode ser bem menor que o estimado inicialmente, canalizando (novamente na história boliviana) a organização das entidades territoriais de NePIOCs para a forma de distritos indígenas, que pertencem ao município, mas que possuem maior flexibilidade na utilização de seus recursos.

O processo de mudança não é linear, apontando caminhos algumas vezes contraditórios, como o do modelo econômico. O governo do MAS, com uma forte visão desenvolvimentista, apostou em primeiro lugar no papel do Executivo no crescimento econômico à custa de retrocessos nas linhas indianistas (SCHAVELZON, 2010, p. 435-436). Por isso a ideia de um "capitalismo andino-amazônico", com fundamentos econômicos na recuperação dos recursos naturais e na nacionalização (LINERA, 2006, p. 28), de onde viriam o capital que poderia impulsionar as outras economias previstas pelo Estado, como a economia comunitária. Em suma, o objetivo seria colocar as rendas dos hidrocarbonetos sob controle do Estado, redistribuindo-a entre comunidades e aplicando no serviço público (QUIJANO, 2006, p. 17-18).

A busca pela interculturalidade não significou o fim de profundas desigualdades econômicas, que serviu ao colonialismo e por ele continua a ser perpetrado. Essas desigualdades influem, principalmente, de dois modos: de um lado retroalimentação diferenças sociais; por outro fragilizando os modos de vida culturais, tradicionais ou comunitários perante o desenvolvimentismo do Estado.

Este último é visível quando da necessidade da aplicação de direitos à prévia consulta frente a interesses do desenvolvimentismo implementado pelos próprios governos que promoveram as constituições, com frequentes relatos de descumprimento tanto na Bolívia como no Equador.

Além disso, trata se de um processo completamente relacionado com o momento político do país, vivenciando avanços e retrocessos, demarcadamente de transição. Uma vez que confrontam conceitos moderno, como nação e soberania, transformando o Estado e a justiça. Santos (2012, p.14) observa que esses processos constituintes inauguram um processo de transição histórica de longo prazo, mas a sociedade vive a curto prazo. Isso fragiliza a transição, que pode ser desviada ou boicotada pela velha política. Portanto, 
esses projetos constituintes estão especialmente sujeitos a um processo de desconstitucionalização.

Outro ponto que já chama atenção na conjuntura inaugurada com a nova constituição, é o frequente choque entre os novos princípios - em especial os relacionados ao bem viver e a mãe Terra - com o modelo econômico de exploração de recursos naturais e do neodesenvolvimentismo empregado pelo governo masista. Essa disputa demonstra que o colonialismo não foi, todavia, extirpado do Estado boliviano, em que pese o reconhecimento de sua existência e o objetivo explícito de descoloniza-lo.

Entre os juristas brasileiros, a nova Constituição boliviana foi recepcionada com uma grande carga de expectativas sobre a transformação que poderia impor ao Estado-nação moderno (WOLKMER, 2010; MAGALHÃES; AFONSO, 2011; OLIVEIRA FILHO, 2014b). Mas a empiria parece confirmar os efeitos do que o Prof. Enzo Bello (2009) chamou de "fetichismo constitucional":

[...] a concepção de fetichismo permite revelar a influência que conceitos metafísicos, como as previsões constitucionais do Novo Constitucionalismo Latino-Americano, podem importar em práticas alienadas, que ocultam a insuficiência de mecanismos jurídicos para a produção de transformações estruturais na sociedade. A questão diz respeito às possibilidades limitadas de transformação social a partir de um fenômeno que não representa uma mudança estrutural das relações materiais da sociedade em questão. Além disso, cabe evidenciar que o aperfeiçoamento dos instrumentos de participação, no âmbito do NCLA, pode representar também uma ferramenta mais sofisticada de promoção da alienação, ocultando de forma ainda mais perfeita as desigualdades estruturais da sociedade capitalista. (BELLO, et al., 2015, p. 12)

Ou seja, esquecemo-nos que a realidade não é transformada apenas pela lei.

\section{CONCLUSÃO}

Como se pode perceber, os povos indígenas latino-americanos, que resistem há séculos ao colonialismo, começam a tomar protagonismo na construção das recentes constituições que surgiram no continente. $\mathrm{O}$ atual momento do constitucionalismo local reflete essa realidade, incorporando demandas e elementos da cosmovisão desses povos e nações, especialmente nos países andinos.

Não à toa, as expectativas criadas pelo texto constitucional, que tem a plurinacionalidade como projeto, foram altas. As previsões fundadas na contribuição 
indígena contrastavam com o modelo de Estado liberal existente, falando em direitos da natureza e pluralismo jurídico.

Entretanto, o período de implementação das novas constituições tem demonstrado a dificuldade de transformação material da realidade indígena nesses Estados. Não são poucos os casos de supressão, por exemplo, do direito à consulta em nome do neodesenvolvimentismo que permeia os governos que promoveram as novas constituições. Da mesma forma exalta-se a Pachamama desde Estados que ainda buscam explorar recursos naturais não renováveis. No presente trabalho, fica demonstrada que a autonomia também sofre revés ao não ser implementada; bem como a descolonização expressa pelos constituintes, quando se parte do período colonial como critério de obtenção de direitos aos indígenas originários campesinos.

A principal conclusão do presente analise é que, para a Bolívia alcançar o objetivo maior de construir um Estado Plurinacional - não só formalmente, mas materialmente necessita novos passos em direção `a uma real descolonização. A forca criativa das nações e povo indígenas originários campesinos não se esgotou com a constituinte, embora tenha sido estancada com o sucesso em adentrar o espaço estatal. Atualmente, através de novas organizações (tais como a CONAIOC - Coordinadora Nacional de Autonomías Indígenas) buscam implementar as autonomias, lidando com a descolonização não só no texto, mas no dia-a-dia da gestão de seus territórios.

A atual Constituição representa um avanço, mas é um projeto político fruto de um período de transição histórica que ainda precisa ser concluído. O constitucionalismo indígena não pode se encerrar com o fim de uma Assembleia Constituinte, mas demanda luta e resistência em sua implementação, principalmente nas tarefas cotidianas que a transformação das instituições antigas demanda.

\section{REFERÊNCIAS}

ALBÓ, X; ROMERO, C. Autonomías indígenas en la realidad boliviana y su nueva Constitución. La Paz: Vicepresidencia del Estado, Presidencia del Honorable Congreso Nacional, 2009.

BELLO, Enzo. Cidadania, alienação e fetichismo constitucional. In: Anais do XVIII Congresso Nacional do CONPEDI, 2009, p. 518-545. 
BELLO, E. et al. Democracia e participação popular: reflexões críticas no contexto do novo constitucionalismo latino-americano. Texto apresentado no IV Congresso Internacional Constitucionalismo e Democracia, Foz do Iguaçu, 2015.

BOLÍVIA. Nueva Constitución Política del Estado Plurinacional de Bolívia, 2009.

BOLÍVIA. Ley n 031 Marco de Autonomías y Descentralización Andrés Ibáñez, 2010.

HARNECKER, Marta; FUENTES, Federico; MAS-IPSP, de Bolívia. Instrumento político que surge de los movimientos sociales. La Paz, 2008.

INSTITUTO NACIONAL DE ESTAdíSTICA DE BOLIVIA. Censo Nacional de Población y Vivienda 2001: Resultados nacionales, 2001.

KYMLICKA, Will. Multicultural citizenship: A liberal theory of minority rights. Oxford: Clarendon Press, 1995.

LINERA, Álvaro G. Indigenous Autonomies and the Multinational State. In: BIALAKOWSKY, Alberto et al. (Comp.). Latin American Critical Thought: Theory and Practice. Buenos Aires: CLACSO, p. 27-82, 2012.

LINERA, Álvaro G. El capitalismo andino-amazónico. Le monde diplomatique, v. 4, p. 38, 2006.

MAGALHÃES, José Luiz Quadros; AFONSO, Henrique W. O Estado Plurinacional da Bolívia e do Equador: matrizes para uma releitura do direito internacional moderno. Revista Brasileira de Direito Constitucional - RBDC, n. 17, p. 263-276, jan./jun. 2011.

MONCAYO, Héctor-León. Las nuevas constituciones en América Latina. Algunas reflexiones de contexto. El Otro Derecho, no 48, p. 135-168, 2013.

OLIVEIRA FILHO, G. B. G. Cultura, identidade e cidadania no novo constitucionalismo latino americano. In: Anais do 40 Seminário Interdisciplinar em Sociologia e Direito - GT 04: CIDADANIA, DIREITO À CIDADE E DESCOLONIALISMO NO ÂMBITO DO NOVO CONSTITUCIONALISMO LATINO AMERICANO. Niterói: PPGSD-UFF v. 4, p. 29-40, 2014a.

OLIVEIRA FILHO, G. B. G. Novo Constitucionalismo Latino-Americano: O Estado Moderno em contextos pluralistas. Revista Culturas Jurídicas, v. 1, n.1, p. 31-50, 2014b. Disponível em: <http://culturasjuridicas.uff.br/index.php/rcj/article/view/41>.

ORTIZ, M. V.; ZAMORANO, I.B. Autonomías Indígenas, Un Proceso a Construir. La Paz, Bolívia: FAM-Bolívia, 2010.

PLATA, Wilfredo. De municipio a autonomía indígena. Los once municipios que transitan a la Autonomía Indígena Originaria Campesina. Reconfigurando territorios. Reforma agraria, control territorial y gobiernos indígenas en Bolívia (Informe 2009) La Paz: Fundación Tierra, 2009.

QUIJANO, Aníbal. Estado-nación y movimientos indígenas en la región Andina: cuestiones abiertas. Osal, v. 7, n. 19, 2006.

SANTOS, Boaventura de Souza. Refundación del Estado em América Latina. Perspectivas desde uma epistemologia del Sur. La Paz: Plural, 2010. 
SCHAVELZON, Salvador. A Assembleia Constituinte da Bolívia: etnografia do nascimento de um Estado Plurinacional. Tese de Doutorado. Niterói: PPGAS-Museu Nacional, 2010.

SCHAVELZON, Salvador. As Categorias Abertas da Nova Constituição Boliviana. Formação do Estado Plurinacional: Alguns Percursos Intelectuais. Revista Lugar Comum, n. 27, 2009, p. 35-60.

STEFANONI, Pablo. El nacionalismo indígena en el poder. Movimientos Sociales y gobiernos en la región Andina. Resistencias y alternativas. Lo político y lo social, 2006, p. 37-44.

TAYLOR, Charles et al. The politics of recognition. Multiculturalism: Examining the politics of recognition, 1994.

VALENÇA, D. Bolívia: crise de Estado, disputa hegemônica e ressignificação democrática. In: BELLO, Enzo; VAL, Eduardo Manuel (Org.). O pensamento pós e descolonial no novo constitucionalismo latino-americano. Caxias do Sul: EDUCS, 2014, p. 87-102.

WOLKMER, Antônio Carlos. Crítica ao Pluralismo na América Latina. Anais do IX Simpósio Nacional de Direito Constitucional - Academia Brasileira de Direito Constitucional, 2010, p. 143-155.

WOLKMER, A.C.; FAGUNDES, Lucas Machado. Tendências Contemporâneas do Constitucionalismo Latino-americano: Estado plurinacional e pluralismo jurídico. Revista Pensar, Fortaleza, v. 16, n. 2, p. 371-408, jul. /dez. 2011, p. 371-408. 